\title{
Correlates of smoking quit attempts: Florida Tobacco Callback
} Survey, 2007

\author{
Evelyn P Davila ${ }^{1}$, Wei Zhao ${ }^{2}$, Margaret Byrne ${ }^{1}$, Monica Webb ${ }^{3}$, \\ Yougie Huang ${ }^{4}$, Kristopher Arheart ${ }^{1}$, Noella Dietz ${ }^{1}$, Alberto Caban-Martinez ${ }^{1}$, \\ Dorothy Parker ${ }^{5}$ and David J Lee*1
}

\begin{abstract}
Address: ${ }^{1}$ Department of Epidemiology and Public Health, University of Miami, USA, ${ }^{2}$ Sylvester Biostatistics Core Resource, University of Miami, Miami, FL, USA, ${ }^{3}$ Department of Psychology, University of Miami, Miami, FL, USA, ${ }^{2}$ Florida Department of Health, Bureau of Epidemiology,

Tallahassee, FL, USA and ${ }^{5}$ Disparities and Community Outreach Core, University of Miami Sylvester Comprehensive Cancer Center, Miami, FL, USA

Email: Evelyn P Davila - edavila1@med.miami.edu; Wei Zhao - wzhao@med.miami.edu; Margaret Byrne - mbyrne2@med.miami.edu; Monica Webb - monicawebb@med.miami.edu; Yougie Huang - youjie_huang@doh.state.fl.us; Kristopher Arheart - karheart@med.miami.edu; Noella Dietz - ndietz@med.miami.edu; Alberto Caban-Martinez - acaban@med.miami.edu; Dorothy Parker - dparker@med.miami.edu; David J Lee* - dlee@med.miami.edu

* Corresponding author
\end{abstract}

Published: 29 June 2009

Tobacco Induced Diseases 2009, 5:10 doi:10.1186/1617-9625-5-10
Received: 3I March 2009

Accepted: 29 June 2009

This article is available from: http://www.tobaccoinduceddiseases.com/content/5/1/10

(C) 2009 Davila et al; licensee BioMed Central Ltd.

This is an Open Access article distributed under the terms of the Creative Commons Attribution License (http://creativecommons.org/licenses/by/2.0), which permits unrestricted use, distribution, and reproduction in any medium, provided the original work is properly cited.

\begin{abstract}
Objective: The public health burden of tobacco-associated diseases in the USA remains high, in part because many people's attempts to quit are unsuccessful. This study examined factors associated with having lifetime or recent attempts to quit smoking among current smokers, based on a telephone survey of Florida adults.

Methods: Data from the 2007 telephone-based Florida Behavioral Risk Factor Surveillance System (BRFSS) and its follow-up survey, the Tobacco Callback Survey, were used to assess determinants of having ever attempted to quit smoking and attempted to quit smoking in the past 12 months. All analyses were conducted using SAS.

Results: Among 3,560 current smokers, $41.5 \%$ reported having tried to quit smoking in the past 12 months while $83.4 \%$ reported having ever tried to quit. Having a history of a tobacco-related medical condition was significantly associated with both recent (Adjusted Odds Ratio (AOR) I.4I [Confidence Interval I.19-I.65]) and lifetime quit attempts (AOR I.43 [I.15-I.79]). Greater nicotine dependence and being advised by a physician to quit smoking were also positively associated with lifetime quit attempts.

Receipt of healthcare provider advice to quit smoking in the past 12 months and a strong belief that quitting following a long history of regular smoking would not result in health benefits and belief that there are health benefits to quitting smoking were associated with lifetime quit attempts.

Conclusion: Targeted smoking cessation interventions are needed for smokers with selected medical conditions and with high nicotine dependence. The importance of physician advice in encouraging individuals to quit is further highlighted.
\end{abstract}




\section{Introduction}

The 1964 Surgeon General's report on the effects of cigarette smoking on respiratory and cardiovascular health prompted interest in ways to decrease the prevalence of smoking [1], which has been a prominent public health goal since the report was issued. However, cigarette smoking continues to be a major determinant of poor health in the United States. Although the prevalence of smoking has declined since the 1964 report [1,2], 43 million adult smokers in the United States continue to smoke, which represents $20 \%$ of the adult population [3]. Research suggests that smoking and secondhand smoke exposure combined were responsible for 438,000 premature deaths, 5.5 million years of potential life lost, and over $\$ 90$ million productivity losses in the United States each year for the period between 1997 and 2001 [4].

Over the years there has been a great deal of research on smoking cessation, including research on predictors of smoking cessation and successful quit attempts. However, given that intention to quit smoking is shown to be one of the key steps in the process towards smoking cessation [5], it is important to study all quit attempts, even those that are not successful [6]. Furthermore, the fact that these individuals are at least trying to quit smoking suggests that they are motivated, but are just unable to maintain longterm abstinence. In order to adequately address all barriers to smoking cessation among these smokers and increase the proportion of successful quit attempts, it is important to understand the characteristics of smokers who have unsuccessfully tried to quit smoking. There is also a sense of urgency with regard to how soon these smokers are reached, particularly since having many failed attempts may result in frustration, fear, defiance, and loss of interest in quitting [7].

Most studies that address determinants of quit attempts are based on specific populations such as adolescents or young adults [8-10], hospital/clinic and/or chronically-ill patients [9,11-14], specific race/ethnic background, or non-US populations [15-19]. Few studies have assessed quit attempts in the general population $[20,21]$. However, these studies, as well as the others in specific populations, have not undertaken comprehensive analysis of the many factors thought to be associated with quit attempts. The lack of such comprehensive analyses limits the identification of factors most strongly associated with quit attempts. Although studies have investigated the relationship between socio-demographic factors and quit attempts, these studies do not adjust for other factors that may play a role in quit attempts. For example, studies have shown that factors such as physician advice to quit smoking $[16,17,22]$, smoking risk perception [14], nicotine dependence $[13,14,20,23,24]$, weight concern $[25,26]$, and history or presence of a tobacco-related con- dition $[12,13,27]$ are associated with quit attempts. In addition, some of these studies on smoking quit attempts are based on individuals who have successfully quit smoking, and thus factors are assessed in relation to successful quit attempts. However, these factors may not relate in the same fashion with unsuccessful quit attempts. The purpose of this study was to thoroughly assess factors associated with having ever or recently (i.e., within the past 12 months) attempted to quit smoking among current smokers, using data from a sample of Florida residents in 2007.

\section{Methods}

\section{Description of data set and sample}

The Behavioral Risk Factor Surveillance System (BRFSS) is a nationwide state-based telephone survey developed to gather data on risk factors for morbidity and mortality among the non-institutionalized, civilian US population 18 years of age and older using disproportionate stratified random sampling. In 2007 the Florida Department of Health conducted a Florida Tobacco Callback Survey with smokers identified in the BRFSS survey who gave callback permission. The Tobacco Callback Survey included questions about smoking patterns, quit attempts, perceived benefits of quitting, and smoking frequency and nicotine dependence. Of the 8,230 current smokers identified in the BRFSS, 6,007 (73.0\%) agreed to be re-contacted of which $2,310(28.1 \%)$ either were not able to be contacted after 15 phone calls made or gave a firm refusal and 137 $(1.7 \%)$ reported that they were no longer smoking and were therefore ineligible to participate. Thus, the analyses for this paper are based on the 3,560 (43.3\%) of the BRFSS smokers who agreed to be contacted, were successfully called and re-contacted, were still smoking, and completed the follow-up interview with no missing values of age and race.

In this study, data from the 2007 Florida BRFSS and Florida Tobacco Callback Survey were one to one matchmerged by participant sequential number. Using data from the BRFSS, we compared the socio-demographic and selected health characteristics of the smokers who did and did not participate in the Tobacco Callback Survey and found differences that were of small magnitude (Table 1). In assessing whether any differences were meaningful, we calculated the effect sizes for selected variables between the respondents and non-respondents. Effect sizes were all $<0.2$, which is considered to be small effect[28]

\section{Definitions and statistical analyses}

Variables for recent and lifetime attempt to quit smoking were defined based on two questions in the Tobacco Callback Survey. Having a recent quit attempt was indicated when a respondent answered "yes" to the question of "Have you tried to quit smoking completely during the past 12 months." A lifetime quit attempt was defined 
Table I: Demographics and SES of current smoker BRFSS vs. Callback survey

\begin{tabular}{|c|c|c|c|c|c|}
\hline \multirow[b]{2}{*}{ Demographics and SES } & \multicolumn{2}{|c|}{ BRFSS } & \multicolumn{2}{|c|}{ Callback } & \multirow[b]{2}{*}{ Effect $^{2}$} \\
\hline & $\mathbf{n}$ & $\%$ & $\mathbf{n}$ & $\%$ & \\
\hline Total participants & 4670 & 100.0 & 3560 & 100.0 & \\
\hline \multicolumn{6}{|l|}{ Age in years } \\
\hline Missing & 39 & 0.8 & 12 & 0.3 & 1.03 \\
\hline $18-39$ yrs & 1122 & 24.0 & 690 & 19.4 & 0.11 \\
\hline $40-54$ yrs & 1712 & 36.7 & 1335 & 37.5 & 0.02 \\
\hline 55 or older & 1797 & 38.5 & 1523 & 42.8 & 0.09 \\
\hline \multicolumn{6}{|l|}{ Gender } \\
\hline Male & 1973 & 42.2 & 1314 & 36.9 & 0.11 \\
\hline Female & 2697 & 57.8 & 2246 & 63.1 & 0.11 \\
\hline \multicolumn{6}{|l|}{ Race/Ethnicity } \\
\hline Missing & 34 & 0.7 & 18 & 0.5 & 0.46 \\
\hline Non-Hispanic White & 3729 & 79.9 & 2980 & 83.7 & 0.10 \\
\hline Non-White or Hispanic & 907 & 19.4 & 562 & 15.8 & 0.09 \\
\hline \multicolumn{6}{|l|}{ Education level } \\
\hline Missing & 30 & 0.6 & 5 & 0.1 & 1.01 \\
\hline Did not graduate High School & 796 & 17.0 & 595 & 16.7 & 0.01 \\
\hline Graduated High School & 1827 & 39.1 & 1304 & 36.6 & 0.06 \\
\hline Attended College or Technical School & 1270 & 27.2 & 1100 & 30.9 & 0.08 \\
\hline Graduated from College or Technical School & 747 & 16.0 & 556 & 15.6 & 0.01 \\
\hline \multicolumn{6}{|l|}{ Income } \\
\hline Missing & 639 & 13.7 & 346 & 9.7 & 1.67 \\
\hline Less than $\$ 15,000$ & 627 & 13.4 & 571 & 16.0 & 0.06 \\
\hline$\$ 15,000$ to less than $\$ 25,000$ & 998 & 21.4 & 808 & 22.7 & 0.03 \\
\hline$\$ 25,000$ to less than $\$ 35,000$ & 617 & 13.2 & 478 & 13.4 & 0.01 \\
\hline$\$ 35,000$ to less than $\$ 50,000$ & 664 & 14.2 & 516 & 14.5 & 0.01 \\
\hline$\$ 50,000$ or more & 1125 & 24.1 & 841 & 23.6 & 0.01 \\
\hline \multicolumn{6}{|l|}{ Have any health care coverage } \\
\hline Not asked or Missing & 10 & 0.2 & 4 & 0.1 & 0.27 \\
\hline No & 1262 & 27.0 & 917 & 25.8 & 0.03 \\
\hline Yes & 3398 & 72.8 & 2639 & 74.1 & 0.03 \\
\hline \multicolumn{6}{|l|}{ Marital status } \\
\hline Missing & 23 & 0.5 & 5 & 0.1 & 0.74 \\
\hline Married & 2026 & 43.4 & 1608 & 45.2 & 0.04 \\
\hline Divorced, widowed, separated & 1812 & 38.8 & 1460 & 41.0 & 0.05 \\
\hline Others (never married, unmarried couple) & 809 & 17.3 & 487 & 13.7 & 0.10 \\
\hline \multicolumn{6}{|l|}{ Children in household } \\
\hline Missing & 23 & 0.5 & 5 & 0.1 & 0.74 \\
\hline No & 3151 & 67.5 & 2427 & 68.2 & 0.01 \\
\hline Yes & 1496 & 32.0 & 1128 & 31.7 & 0.01 \\
\hline \multicolumn{6}{|l|}{ Body Mass Index } \\
\hline Missing & 226 & 4.8 & 59 & 1.7 & 0.67 \\
\hline Neither overweight nor obese & 2017 & 43.2 & 1458 & 41.0 & 0.05 \\
\hline Obese & 931 & 19.9 & 858 & 24.1 & 0.03 \\
\hline Overweight & 1496 & 32.0 & 1185 & 33.3 & 0.10 \\
\hline \multicolumn{6}{|l|}{ Weight change in the past year } \\
\hline Missing & 301 & 6.4 & 101 & 2.8 & 0.72 \\
\hline Gain/loss $<=3 \mathrm{~kg}$ & 2668 & 57.1 & 1950 & 54.8 & 0.05 \\
\hline Loss $>3 \mathrm{~kg}$ & 936 & 20.0 & 816 & 22.9 & 0.07 \\
\hline Gain $>3 \mathrm{~kg}$ & 765 & 16.4 & 693 & 19.5 & 0.08 \\
\hline \multicolumn{6}{|l|}{ Intentional weight change } \\
\hline Missing & 28 & 0.6 & 23 & 0.6 & 0.10 \\
\hline No change & 2396 & 51.3 & 1588 & 44.6 & 0.13 \\
\hline Intentional & 783 & 16.8 & 687 & 19.3 & 0.07 \\
\hline Not intentional & 1463 & 31.3 & 1262 & 35.4 & 0.09 \\
\hline \multicolumn{6}{|l|}{ Ever had any medical condition } \\
\hline No & 2573 & 55.1 & 1757 & 49.4 & 0.12 \\
\hline Yes & 2097 & 44.9 & 1803 & 50.6 & 0.12 \\
\hline
\end{tabular}


Table I: Demographics and SES of current smoker BRFSS vs. Callback survey (Continued)

\begin{tabular}{|c|c|c|c|c|c|}
\hline \multicolumn{6}{|c|}{ Binge drinking } \\
\hline Missing & 343 & 7.3 & 71 & 2.0 & 1.07 \\
\hline No & 3374 & 72.2 & 2817 & 79.1 & 0.16 \\
\hline Yes & 953 & 20.4 & 672 & 18.9 & 0.04 \\
\hline \multicolumn{6}{|c|}{ Heavy alcohol consumption } \\
\hline Missing & 347 & 7.4 & 82 & 2.3 & 1.03 \\
\hline No & 3778 & 80.9 & 3072 & 86.3 & 0.14 \\
\hline Yes & 545 & 11.7 & 406 & 11.4 & 0.01 \\
\hline
\end{tabular}

a Effect sizes between two independent proportion (BRFSS and Callback).

when a respondent answered "yes" to the question of "Have you ever tried to quit smoking completely." Factors that are potentially associated with attempts to quit were selected based on literature review on successful quit attempts. These variables included demographic characteristics (e.g., age, race/ethnicity, gender, marital status, educational attainment, number of children), average of number of days per month smoked, number of cigarettes smoked per day, perceived health benefit of quitting based on the question "If a person has smoked a pack of cigarettes a day for more than 20 years, there is little health benefit to quitting smoking," body mass index (BMI), weight change, healthcare provider advice to quit smoking, nicotine dependence, and history of a tobaccorelated medical condition.

Nicotine dependence was a composite variable derived from a factor analysis ( 6 items, score range 1-4, $\alpha=0.81$, a higher score indicates more nicotine dependence, then classified into 3 levels: heavier dependence if score $>=5$, moderate dependence if $2<$ score $<5$ and lighter dependence if score $<=2$ ) which included items such as: "Do you have trouble going more than a few hours without smoking;" "Even in a bad rainstorm, if you ran out of cigarettes, you would probably go to the store to get some more"; "When you go without smoking for a few hours, you experience craving." The questions used for our definition of nicotine dependence are based on slight modifications of questions from the Nicotine Dependence Syndrome Scale (NDSS) [29]. The measure for a history of tobacco-related medical condition (Yes/No) was created based on self report of any of the following medical conditions: diabetes, high blood pressure, heart attack, coronary heart disease (CHD), angina, stroke, and asthma. If the participant answered yes to any of these medical conditions they were considered to have a "tobacco-related medical condition." All variables used in the present study are based on selfreported data as BRFSS is a survey administered via the telephone.

Descriptive statistics of categorical data are presented as percentages, and continuous data are presented as means and standard deviations (SD). Simple logistic regressions were first conducted for all the potential independent var- iables. To reduce the possibility of confounding in the multiple regression models, variables with a p-value less than or equal to 0.20 in simple logistic regression models were included in initial multiple logistic regression models simultaneously to identify factors independently associated with recent and lifetime smoking quit attempts [30]. Age, gender and race/ethnicity were included in the models regardless of the significance level. Covariates were assessed for pre-specified interactions. Comparisons resulting in a p-value of 0.05 or less were considered to be statistically significant. SAS version 9.2 (SAS Institute, Inc; Cary, NC) was used for all of the analyses. This study was approved by the University of Miami Institutional Review Board.

\section{Results}

The sample characteristics are shown in Table 2. The majority of the 3,560 current smokers in the Tobacco Callback Survey reported their race as White $(84.1 \%)$ with a slightly greater proportion of females than males $(63.1 \%)$. Over $83 \%$ of the participants reported a high school education or above. More than 58\% were overweight or obese using standard definitions. Approximately $42 \%$ reported to have tried to quit smoking completely during the past 12 months while about $83 \%$ reported to have ever tried to quit smoking completely. More than $50 \%$ of these smokers reported ever having a tobacco-related medical condition.

There were no significant first order interactions between any of the variables, including the variables "ever had a tobacco-related medical condition" and "provider advice for quitting smoking." Thus, no interaction terms were included in the final regression models.

\section{Correlates of quit attempts in the past 12 months}

Females were slightly but significantly more likely to report a quit attempt in the past 12 months than males (Adjusted Odds Ratio [AOR] 1.19, [95\% Confidence Interval, 1.00-1.40]); relative to non-Hispanic Whites, non-Hispanic Blacks were also more likely to make a quit attempt (AOR 1.63 [1.15-2.30]) (Table 3). Compared to adults 18-39 years of age, adults $40-54$ years of age and 55 years of age and older were less likely to report a quit 
Table 2: Sample Characteristics: Florida Tobacco Callback Survey, Behavioral Risk Factor Surveillance System, $2007(\mathrm{n}=3560)$

\begin{tabular}{|c|c|c|}
\hline Variable & $\mathbf{n}$ & $\%$ \\
\hline \multicolumn{3}{|l|}{ Age in years } \\
\hline $18-39$ yrs & 690 & 19.5 \\
\hline $40-54$ yrs & 1335 & 37.6 \\
\hline$>=55 \mathrm{yrs}$ & 1523 & 42.9 \\
\hline \multicolumn{3}{|l|}{ Gender } \\
\hline Female & 2246 & 63.1 \\
\hline \multicolumn{3}{|l|}{ Race/Ethnicity } \\
\hline White, non-Hispanic & 2980 & 84.1 \\
\hline Black, non-Hispanic & 217 & 6.1 \\
\hline Hispanic & 156 & 4.4 \\
\hline Other race, non-Hispanic & 189 & 5.3 \\
\hline \multicolumn{3}{|l|}{ Education level } \\
\hline Did not graduate High School & 595 & 16.7 \\
\hline Graduated High School & 1304 & 36.7 \\
\hline Attended College or Technical School & 1100 & 30.9 \\
\hline Graduated from College or Technical School & 556 & 15.6 \\
\hline \multicolumn{3}{|l|}{ Marital status } \\
\hline Married & 1608 & 45.2 \\
\hline Divorced, widowed, separated & 1460 & 41.1 \\
\hline Others (never married, unmarried couple) & 487 & 13.7 \\
\hline Children in household & 1128 & 31.7 \\
\hline \multicolumn{3}{|l|}{ Body Mass Index } \\
\hline Neither overweight nor obese & 1458 & 41.7 \\
\hline Overweight & 1185 & 33.9 \\
\hline Obese & 858 & 24.5 \\
\hline \multicolumn{3}{|l|}{ Weight change in the past year } \\
\hline Gain/loss $<=3 \mathrm{~kg}$ & 1950 & 56.4 \\
\hline Loss $>3 \mathrm{~kg}$ & 816 & 23.6 \\
\hline Gain $>3 \mathrm{~kg}$ & 693 & 20.0 \\
\hline \multicolumn{3}{|l|}{ Intentional weight change } \\
\hline No change & 1588 & 44.9 \\
\hline Intentional & 687 & 19.4 \\
\hline Not intentional & 1262 & 35.7 \\
\hline Ever had any medical condition & 1803 & 50.7 \\
\hline Binge drinking & 672 & 19.3 \\
\hline Heavy alcohol consumption & 406 & 11.7 \\
\hline \multicolumn{3}{|l|}{ Nicotine dependence } \\
\hline Lighter dependence & 1295 & 38.8 \\
\hline Moderate dependence & 910 & 27.3 \\
\hline Heavier dependence & 1134 & 34.0 \\
\hline \multicolumn{3}{|l|}{ Heath care provider advice to stop smoking in the past 12 months } \\
\hline No/Non visit & 1285 & 38.2 \\
\hline Yes & 2079 & 61.8 \\
\hline \multicolumn{3}{|c|}{ Perceived benefit of quitting: " If long time smoker, little health benefit to quitting" } \\
\hline Strongly agree & 241 & 7.4 \\
\hline Agree & 625 & 19.2 \\
\hline Disagree & 1368 & 42.1 \\
\hline Strongly disagree & 1018 & 31.3 \\
\hline Tried to quit smoking completely during the past 12 months & 1409 & 41.5 \\
\hline \multirow[t]{2}{*}{ Ever tried to quit smoking completely } & 2808 & 82.7 \\
\hline & Mean & std \\
\hline Number of years smoked & 33.6 & 14.3 \\
\hline Number of cigarettes smoked per day & 18.6 & 11.0 \\
\hline Number of days smoked cigarettes in the past 30 days & 27.6 & 6.6 \\
\hline Number of cigarettes smoked per day in the past 30 days & 17.4 & 11.1 \\
\hline
\end{tabular}


Table 3: Multiple Logistic Regression of Smoking Quit Attempts, Florida Tobacco Callback Survey, Behavioral Risk Factor Surveillance System, 2007a

\begin{tabular}{|c|c|c|c|c|c|c|c|c|}
\hline \multirow[b]{3}{*}{ Variable } & \multicolumn{8}{|c|}{ Smoking Quit Attempt } \\
\hline & \multicolumn{4}{|c|}{$\begin{array}{c}\text { Past } 12 \text { months } n=2917 \\
\text { Yes }=1230(42.2 \%)\end{array}$} & \multicolumn{4}{|c|}{$\begin{array}{l}\text { Lifetime } n=2915 \\
\text { Yes }=2429(83.3 \%)\end{array}$} \\
\hline & $\mathbf{A O R}^{\mathbf{b}}$ & L95c & U95d & P-value & AOR & L95 & U95 & P-value \\
\hline \multicolumn{9}{|l|}{ Age in years } \\
\hline $18-39 y r s$ & 1.000 & & & & 1.000 & & & \\
\hline $40-54$ yrs & 0.787 & 0.625 & 0.991 & 0.0417 & 1.572 & 1.185 & 2.084 & 0.0017 \\
\hline$>=55 \mathrm{yrs}$ & 0.706 & 0.538 & 0.926 & 0.0119 & 1.290 & 0.960 & 1.733 & 0.0914 \\
\hline \multicolumn{9}{|l|}{ Sex } \\
\hline Male & 1.000 & & & & 1.000 & & & \\
\hline Female & 1.186 & 1.002 & 1.402 & 0.0470 & 1.029 & 0.828 & 1.278 & 0.7986 \\
\hline \multicolumn{9}{|l|}{ Race/ethnicity } \\
\hline White-Non-Hispanic & 1.000 & & & & 1.000 & & & \\
\hline Black-Non-Hispanic & 1.625 & 1.148 & 2.299 & 0.0061 & 0.793 & 0.513 & 1.226 & 0.2969 \\
\hline Hispanic & 1.025 & 0.684 & 1.537 & 0.9039 & 0.607 & 0.384 & 0.960 & 0.0328 \\
\hline Other race, Non-Hispanic & 1.099 & 0.785 & 1.538 & 0.5843 & 1.047 & 0.663 & 1.653 & 0.8430 \\
\hline \multicolumn{9}{|l|}{ Education level } \\
\hline Did not graduate High School & 1.000 & & & & 1.000 & & & \\
\hline Graduated High School & 0.779 & 0.615 & 0.986 & 0.0382 & 1.013 & 0.755 & 1.359 & 0.9320 \\
\hline Attended College or Technical School & 0.840 & 0.658 & 1.073 & 0.1621 & 1.439 & 1.044 & 1.984 & 0.0264 \\
\hline Graduated from College or Technical School & 0.767 & 0.577 & 1.021 & 0.0688 & 1.128 & 0.782 & 1.627 & 0.5197 \\
\hline \multicolumn{9}{|l|}{ Marital status } \\
\hline Married & 1.000 & & & & 1.000 & & & \\
\hline Divorced, widowed, separated & 1.140 & 0.962 & 1.351 & 0.1299 & 0.800 & 0.638 & 1.004 & 0.0538 \\
\hline Others (never married, unmarried couple) & 1.007 & 0.782 & 1.297 & 0.9567 & 0.773 & 0.568 & 1.051 & 0.1003 \\
\hline \multicolumn{9}{|l|}{ Children in household } \\
\hline Yes vs. No & 1.039 & 0.855 & 1.264 & 0.6981 & $N A^{e}$ & & & \\
\hline \multicolumn{9}{|l|}{ Weight change the past year } \\
\hline Gain/loss $<=3 \mathrm{~kg}$ & 1.000 & & & & 1.000 & & & \\
\hline Loss $>3 \mathrm{~kg}$ & 1.377 & 1.043 & 1.817 & 0.0242 & 1.206 & 0.831 & 1.749 & 0.3243 \\
\hline Gain $>3$ kg & 1.288 & 0.978 & 1.696 & 0.0716 & 1.024 & 0.716 & 1.464 & 0.8978 \\
\hline \multicolumn{9}{|l|}{ Intentional weight change } \\
\hline No change & 1.000 & & & & 1.000 & & & \\
\hline Intentional & 1.088 & 0.802 & 1.475 & 0.5894 & 1.070 & 0.715 & 1.599 & 0.7426 \\
\hline Not intentional & 1.163 & 0.907 & 1.492 & 0.2339 & 0.954 & 0.694 & 1.313 & 0.7730 \\
\hline \multicolumn{9}{|l|}{ Ever had tobacco-related medical condition } \\
\hline No & 1.000 & & & & 1.000 & & & \\
\hline Yes & 1.405 & 1.193 & 1.654 & $<.0001$ & 1.433 & 1.154 & 1.779 & 0.0011 \\
\hline \multicolumn{9}{|l|}{ Binge drinking } \\
\hline No & 1.000 & & & & NA & & & \\
\hline Yes & 0.883 & 0.702 & 1.111 & 0.2888 & & & & \\
\hline \multicolumn{9}{|l|}{ Heavy alcohol consumption } \\
\hline No & 1.000 & & & & 1.000 & & & \\
\hline Yes & 1.023 & 0.773 & 1.353 & 0.8746 & 0.821 & 0.606 & 1.112 & 0.2032 \\
\hline \multicolumn{9}{|l|}{ Nicotine dependence } \\
\hline Lighter dependence & NA & & & & 1.000 & & & \\
\hline Moderate dependence & & & & & 1.526 & 1.174 & 1.984 & 0.0016 \\
\hline Heavier dependence & & & & & 1.827 & 1.387 & 2.404 & $<.0001$ \\
\hline \multicolumn{9}{|c|}{ Heath care provider advice to stop smoking in the past 12 months } \\
\hline No/no visit & 1.000 & & & & 1.000 & & & \\
\hline Yes & 1.534 & 1.302 & 1.807 & $<.0001$ & 1.564 & 1.273 & 1.922 & $<.0001$ \\
\hline $\begin{array}{l}\text { Perceived benefit of quitting: "If long time } \\
\text { benefit to quitting" }\end{array}$ & & & & & & & & \\
\hline Strongly agree & 1.000 & & & & 1.000 & & & \\
\hline Agree & 0.785 & 0.557 & 1.107 & 0.1680 & 0.799 & 0.537 & 1.189 & 0.2689 \\
\hline Disagree & 0.909 & 0.661 & 1.251 & 0.5585 & 1.157 & 0.791 & 1.692 & 0.4528 \\
\hline Strongly disagree & 1.217 & 0.878 & 1.687 & 0.2392 & 2.146 & 1.419 & 3.247 & 0.0003 \\
\hline
\end{tabular}


Table 3: Multiple Logistic Regression of Smoking Quit Attempts, Florida Tobacco Callback Survey, Behavioral Risk Factor Surveillance System, 2007a (Continued)

\begin{tabular}{|c|c|c|c|c|c|c|c|c|}
\hline \multicolumn{9}{|c|}{ Number of cigarettes smoked per day } \\
\hline Every one cigarette increased & 1.005 & 0.995 & 1.014 & 0.3195 & 1.007 & 0.994 & 1.021 & 0.2964 \\
\hline \multicolumn{9}{|c|}{ Number of days smoked cigarettes in the past 30 days } \\
\hline Every one day increased & 0.958 & 0.946 & 0.971 & $<.0001$ & NA & & & \\
\hline \multicolumn{9}{|c|}{ Number of cigarettes smoked per day in the past 30 days } \\
\hline Every one cigarette increased & 0.988 & 0.978 & 0.998 & 0.0162 & 0.977 & 0.964 & 0.990 & 0.0006 \\
\hline
\end{tabular}

attempt in the previous 12 months (AOR 0.79 [0.630.99]; and AOR 0.71 [0.54-0.93], respectively). Smokers who graduated from high school were less likely to have reported a recent quit attempt compared to smokers who did not graduate from high school (AOR 0.78 [0.620.99]). Compared to those reporting no weight changes, smokers who reported a weight loss of $3 \mathrm{~kg}$ or greater in the previous 12 months were more likely to have made a quit attempt during the previous 12 months (AOR 1.38 [1.04-1.82]). Report of at least one tobacco-related medical condition was associated with increased odds of a recent quit attempt (AOR 1.41 [1.19-1.65]). Smokers who received healthcare-provider advice to quit smoking in the past 12 months were more likely to report a quit attempt during the same time period (AOR 1.53 [1.301.81]). Both the number of days smoking and the amount smoked in the previous 30 days were associated with lower odds of a 12-month quit attempt.

\section{Correlates of Lifetime Quit Attempts}

Odds of a lifetime history of at least one quit attempt was significantly higher in adults 40-54 years of age relative to adults 18-39 years of age (AOR 1.57 [1.19-2.08]) (Table 3). Relative to White non-Hispanics, Hispanic smokers were less likely to report a lifetime quit attempt (AOR 0.61 [0.38-0.96]) Smokers who had attended some college or technical school had a greater odds of a lifetime quit attempt relative to smokers who did not complete high school (AOR 1.44 [1.04-1.98]). Reports of at least one tobacco-related medical condition were associated with increased odds of an ever quit attempt (AOR 1.43 [1.151.78]). Compared to participants with lower levels of nicotine dependence, smokers with moderate and heavy dependence were more likely to have reported at least one quit attempt in their lifetime (AOR 1.53 [1.17-1.98]; and AOR 1.83 [1.39-2.40], respectively). Receipt of healthcare provider advice to quit smoking in the past 12 months was associated with increased odds of a lifetime quit attempt (AOR 1.56 [1.27-1.92]). Compared to those who strongly believed that quitting following a long history of regular smoking would not result in health benefits, smokers who strongly disagreed with this statement were more likely to report a lifetime quit attempt (AOR 2.15 [1.42-3.25]. Finally, the odds of a lifetime quit attempt were inversely associated with the number of cigarettes smoked in the past 30 days.

\section{Discussion}

Most smokers have thought about quitting smoking at one point or another, for various reasons. We found that about eight in 10 Florida smokers have attempted to quit at some point in their lifetime, while four in 10 Florida smokers reported having recently tried to quit. However, the fact that they are still smoking highlights the difficulty most smokers have with achieving successful cessation as well as the importance of characterizing individuals who at least attempt to quit, since they may be more likely to benefit from smoking cessation programs. In this study, we assessed factors associated with ever attempting to quit smoking and recent quit attempts among a sample of current adult smokers in Florida.

In the present study, older smokers were more likely than younger smokers to have ever attempted quitting smoking but were less likely to have tried quitting in the past 12 months, even after controlling for nicotine dependence, perceived benefits of quitting, smoking risk perception, and history or presence of tobacco-related medical conditions. This finding is consistent with another US population based survey of smokers which found older smokers to be least likely to attempt quitting in the past year and be less likely to be successful at quitting [20]. A potential explanation for the difference in quit attempts by age group could be due to resistance to smoking cessation advice due to difficulty quitting, particularly those with many failed attempts, as well as due to changes in social norms regarding tobacco use [20]. It could also be that young smokers try to quit smoking more frequently than older smokers; however the number of quit attempts is not known. We also found that non-Hispanic blacks were the most likely to have reported a quit attempt in the past 12 months while Hispanics were the least likely to have tried quitting smoking in their lifetime, even after controlling for potential confounders. A US population based survey also found blacks to be more likely to report a recent quit attempt although they were least likely to be successful [20]. Again, racial/ethnic differences in quit attempts could be related to social and cultural norms as well as frequency of quit attempts.

The results also showed that history of having a tobaccorelated medical condition was associated with greater likelihood of having attempted to quit smoking, both in the 
last 12 months or in their lifetime. This finding is not entirely surprising given that one reason individuals give for attempting to quit is their health $[17,31,32]$. Furthermore, when smokers have been asked if being diagnosed with a medical condition (e.g., heart disease) would increase their desire to quit smoking, the majority have agreed [12]. Studies have also shown a link between diagnosis of cardiovascular disease and increased motivation to quit smoking and smoking cessation $[11,33,34]$. In addition, nationally representative data do show the prevalence of smoking to be lower among adults with a history of stroke or myocardial infarction (18\%) compared to adults without a history of cardiovascular events (26\%) [35]. However, in a study of emergency department patients it was found that patients with a diagnosis of a cigarette-related medical condition (i.e., cardiovascular and respiratory diseases, peptic ulcer disease, and cancers such as of the lip, esophagus, lung, etc.) were less motivated to quit smoking when compared to smokers without such conditions [13]. Nevertheless, the desire to quit smoking may be contingent on whether the smoker believes their medical condition is related to their smoking, and/or whether they believe quitting will help their condition (since it is already present). In fact, in the present study we did find that smokers who perceive that there are health benefits to quitting smoking are more likely to have ever attempted to quit smoking, which is consistent with a study of emergency patients [14].

We also found that greater level of nicotine dependence was associated with being more likely to have ever attempted to quit smoking, although a statistically significant association was not observed for recent quit attempts. Although our findings are plausible given that greater nicotine dependence has been associated with readiness to quit smoking [14], our findings are inconsistent with other studies that have noted an inverse relationship between degree of nicotine dependence and quit attempts $[20,24]$. However, the differing findings could be related to difference in the definition of nicotine dependence. In agreement with previous studies however [24], we found greater number of smoked cigarettes per day in the past 30 days was inversely related to both recent and lifetime quit attempts. Although the association between nicotine dependence and quit attempts are not entirely clear, our findings suggest that highly dependent smokers are not giving up on quitting smoking and recognize the importance of quitting.

One of the very encouraging findings from our study was related to healthcare provider advice. In agreement with previous studies $[16,17,22,36,37]$, we found that smokers who were advised by their healthcare provider to stop smoking were about $50 \%$ more likely to attempt to quit smoking, both in their lifetime and recently. Thus, con- sistent with the Public Health Service Clinical Practice Guidelines Treating Tobacco Use and Dependence [38], healthcare providers should continue to advise their patients to stop smoking, regardless of the frequency of smoking by their patients or other patient characteristics [36]. The importance of such advice is greatest for individuals with medical conditions, given the greater contact these smokers have with the healthcare system. In fact, increasing to $85 \%$ the proportion of healthcare professionals who counsel their high-risk patients (e.g., with coronary heart disease) about smoking cessation is one Healthy People 2010 goal [39].

Finally we found that those who lost more than $3 \mathrm{~kg}$ in the past year were more likely to have recently tried to quit smoking. This finding could be due to those with a medical condition (i.e. being medically ill), who lost weight because of their illness, deciding to quit smoking as part of their treatment or recovery regimen. Alternatively, it might be that these individuals are making an overall effort to improve their health, including both weight loss and smoking cessation attempts.

There are several limitations to this study. First, a number of variables that may also be related to quit attempts were not available in the dataset. These include extent of knowledge of the health effects associated with smoking, diagnosis of tobacco related cancers, diagnosis of mental health conditions such as depression, and the smoking status of the family and friends particularly if these individuals live with the participant $[8,20,40]$. Second, we do not know the extent of participants' awareness and perceived effectiveness of smoking cessation support, factors which have been associated with greater likelihood of a quit attempt [41]. It would have also been beneficial to know the frequency of quit attempts as well as the timing of these quit attempts. Finally, the results may not be generalized to other populations outside Florida or the United States.

\section{Conclusion}

In conclusion, we found smokers who had a tobaccorelated medical condition, who had greater nicotine dependence, who were advised by their physician to quit smoking, and/or who strongly believed that there are health benefits to quitting smoking were more likely to have smoking quit attempts, either in the past 12 months or ever. In addition, many older smokers appear have given up on quitting smoking given that they are more likely to have ever tried quitting smoking yet not in the past 12 months. However, Blacks and Hispanics appear have tried quitting smoking more recently than in the past. The present study further highlights the importance of awareness of the health implications associated with smoking, particularly if education is provided by a health 
care provider. Given blacks and older smokers may be less successful at quit smoking [20], these groups should be targeted for smoking cessation education. Further research is needed to understand the relationship between nicotine dependence, race/ethnicity, and quit attempts however. In addition, research is needed to characterize smokers with tobacco-related medical conditions and/or greater nicotine dependence in order to develop targeted smoking cessation interventions. Nevertheless, the information provided by this study can guide the development of targeted intervention programs for smokers who appear to want to quit.

\section{Competing interests}

The authors declare that they have no competing interests.

\section{Authors' contributions}

ED was the lead author of the manuscript. WZ managed the data and performed all statistical analyses. MB, MW, $\mathrm{YH}, \mathrm{KA}, \mathrm{ND}, \mathrm{AC}$, and DL assisted in the writing of the manuscript. YH and KA also provided statistical support. In addition, $\mathrm{YH}$ provided the data and assisted with data management issues. DL was the PI for the grant funding the study. All authors read and approved the final manuscript version.

\section{Acknowledgements}

This study was funded in part by the Florida Department of Health and the James \& Esther King Biomedical Research Program Team Science Project Grant.

\section{References}

I. U.S. Department of Health and Human Services: Reducing the Health Consequences of Smoking: 25 years of progress. A report of the Surgeon General. U. S. Department of Health and Human Services, Public Health Service, Centers for Disease Control, Center for Chronic Disease Prevention and Health Promotion, Office on Smoking and Health. DHSS Publication No. (CDC) 89-84II 1989.

2. Marlow SP, Stoller JK: Smoking cessation. Respiratory care 2003, 48(I 2): I 238- 1254 .

3. Centers for Disease Control and Prevention (CDC): Cigarette Smoking Among Adult. MMWR 2008, 57(45): I 221 - 1248.

4. Centers for Disease Control and Prevention: Annual smokingattributable mortality, years of potential life lost, and productivity losses - United States, 1997-200 I. MMWR Morb Mortal Wkly Rep 2005, 54(25):625-628.

5. Farkas AJ, Pierce JP, Zhu SH, Rosbrook B, Gilpin EA, Berry C, Kaplan RM: Addiction versus stages of change models in predicting smoking cessation. Addiction (Abingdon, England) 1996, 9I(9): $127 \mid-1280$.

6. Derby CA, Lasater TM, Vass K, Gonzalez S, Carleton RA: Characteristics of smokers who attempt to quit and of those who recently succeeded. American journal of preventive medicine 1994, I 0(6):327-334.

7. Wolburg : College students' responses to antismoking messages: Denial, defiance, and other Boomerang Effects. The journal of consumer affairs 2006, 40(2):294-323.

8. Tucker JS, Ellickson PL, Orlando M, Klein DJ: Predictors of attempted quitting and cessation among young adult smokers. Preventive medicine 2005, 4 I (2):554-56I.

9. Kip KE, McCreath HE, Roseman JM, Hulley SB, Schreiner PJ: Absence of risk factor change in young adults after family heart attack or stroke: the CARDIA Study. American journal of preventive medicine 2002, 22(4):258-266.
10. Rose JS, Chassin L, Presson CC, Sherman SJ: Prospective predictors of quit attempts and smoking cessation in young adults. Health Psychol 1996, I 5(4):261-268.

II. Rigotti NA, Singer DE, Mulley AG, Thibault GE: Smoking cessation following admission to a coronary care unit. Journal of General Internal Medicine 1991, 6:305-3II.

12. Hyman DJ, Simons-Morton DG, Dunn JK, Ho K: Smoking, smoking cessation, and understanding of the role of multiple cardiac risk factors among the urban poor. Preventive medicine 1996, 25(6):653-659.

13. Bernstein SL, Cannata M: Nicotine dependence, motivation to quit, and diagnosis in emergency department patients who smoke. Addictive behaviors 2006, 3 I (2):288-297.

14. Bock BC, Becker BM, Partridge R, Niaura R: Are emergency chest pain patients ready to quit smoking? Preventive cardiology 2007, 10(2):76-82.

15. Szanto Z, Susanszky E, Kopp M: Relationships between unfavourable health status and smoking cessation attempts in Hungary. Sozial- und Praventivmedizin 2005, 50(5):324-333.

16. Yong HH, Borland R, Siahpush M: Quitting-related beliefs, intentions, and motivations of older smokers in four countries: findings from the International Tobacco Control Policy Evaluation Survey. Addictive behaviors 2005, 30(4):777-788.

17. Vangeli E, West R: Sociodemographic differences in triggers to quit smoking: Findings from a national survey. Tobacco control 2008, I7(6):410-415

18. Wakefield M, Ruffin R, Campbell D, Roberts L, Wilson D: Smokingrelated beliefs and behaviour among adults with asthma in a representative population sample. Aust N Z J Med. 1995, 25(I): 12-17.

19. Abdullah AS, Yam HK: Intention to quit smoking, attempts to quit, and successful quitting among Hong Kong Chinese smokers: population prevalence and predictors. Am J Health Promot 2005, 19(5):346-354.

20. Messer K, Trinidad DR, Al-Delaimy WK, Pierce JP: Smoking cessation rates in the United States: a comparison of young adult and older smokers. American journal of public health 2008, 98(2):317-322.

21. Fagan P, Shavers V, Lawrence D, Gibson JT, Ponder P: Cigarette smoking and quitting behaviors among unemployed adults in the United States. Nicotine Tob Res 2007, 9(2):24I-248.

22. Kreuter MW, Chheda SG, Bull FC: How does physician advice influence patient behavior? Evidence for a priming effect. Archives of family medicine 2000, 9(5):426-433.

23. Zhou X, Nonnemaker J, Sherrill B, Gilsenan AW, Coste F, West R: Attempts to quit smoking and relapse: factors associated with success or failure from the ATTEMPT cohort study. Addictive behaviors 2009, 34(4):365-373.

24. Fagan $\mathrm{P}$, Augustson $\mathrm{E}$, Backinger $\mathrm{CL}$, O'Connell ME, Vollinger RE Jr, Kaufman A, Gibson JT: Quit attempts and intention to quit cigarette smoking among young adults in the United States. American journal of public health 2007, 97(8): 14|2-1420.

25. French SA, Jeffery RW, Pirie PL, McBride CM: Do weight concerns hinder smoking cessation efforts? Addictive behaviors 1992, I7(3):219-226.

26. French SA, Jeffery RW, Klesges LM, Forster JL: Weight concerns and change in smoking behavior over two years in a working population. American journal of public health 1995, 85(5):720-722.

27. Rigotti NA, Munafo MR, Murphy MF, Stead LF: Interventions for smoking cessation in hospitalised patients. Cochrane Database Syst Rev 200I:CD00 I837.

28. Cohen J: Statistical Power Analyses for the Behavioral Sciences. 2nd edition. New Jersey, Lawrence Erlbaum Associates; 1988.

29. Shiffman S, Brockwell SE, Pillitteri JL, JG G: Individual differences in adoption of treatment for smoking cessation: Demographic and smoking history characteristics. Drug Alcohol Depend. 2008, 93(I-2): |2|-|3|.

30. Hosmer DW, S L: Applied Logist Regression. Second edition. John Wiley \& Sons, Inc New York, NY; 2000.

31. Duncan CL, Cummings SR, Hudes ES, Zahnd E, Coates TJ: Quitting smoking: reasons for quitting and predictors of cessation among medical patients. J Gen Intern Med 1992, 7(4):398-404.

32. Wray LA, Herzog AR, Willis RJ, Wallace RB: The impact of education and heart attack on smoking cessation among middleaged adults. J Health Soc Behav. 1998, 39(4):27I-294. 
33. Ives SP, Heuschmann PU, Wolfe CD, Redfern J: Patterns of smoking cessation in the first 3 years after stroke: the South London Stroke Register. Eur J Cardiovasc Prev Rehabil 2008, I 5(3):329-335.

34. Salive ME, Cornoni-Huntley J, LaCroix AZ, Ostfeld AM, Wallace RB, Hennekens $\mathrm{CH}$ : Predictors of smoking cessation and relapse in older adults. American journal of public health 1992, 82(9): |268-|27|.

35. Qureshi Al, Suri MF, Guterman LR, Hopkins LN: Ineffective secondary prevention in survivors of cardiovascular events in the US population: report from the Third National Health and Nutrition Examination Survey. Archives of internal medicine 200I, 16I(13):162I-1628.

36. Tong EK, Ong MK, Vittinghoff E, Perez-Stable EJ: Nondaily smokers should be asked and advised to quit. American journal of preventive medicine 2006, 30(I):23-30.

37. Gilpin EA, Pierce JP, Johnson M, Bal D: Physician advice to quit smoking: results from the 1990 California Tobacco Survey. J Gen Intern Med I993, 8( I0):549-553.

38. Fiore M, Bailey W, Cohen S: Treating Tobacco Use and Dependence. Quick Reference Guide for Clinicians. Rockville, MD:. U.S. Department of Health and Human Services. Public Health Service; 2000.

39. Centers for Disease Control and Prevention and National Institute of Health: Healthy People. Cancer 2010 [http://www.healthypeo ple.gov/document $/ \mathrm{html} /$ volumel/03cancer.htm].

40. Okoli CT, Browning S, Rayens MK, Hahn EJ: Secondhand tobacco smoke exposure, nicotine dependence, and smoking cessation. Public health nursing (Boston, Mass) 2008, 25(I):46-56.

4I. Hammond D, McDonald PW, Fong GT, Borland R: Do smokers know how to quit? Knowledge and perceived effectiveness of cessation assistance as predictors of cessation behaviour. Addiction (Abingdon, England) 2004, 99(8): 1042-1048.

Publish with Bio Med Central and every scientist can read your work free of charge

"BioMed Central will be the most significant development for disseminating the results of biomedical research in our lifetime. "

Sir Paul Nurse, Cancer Research UK

Your research papers will be:

- available free of charge to the entire biomedical community

- peer reviewed and published immediately upon acceptance

- cited in PubMed and archived on PubMed Central

- yours - you keep the copyright

Submit your manuscript here:

http://www.biomedcentral.com/info/publishing_adv.asp
BiolMedcentral 